\title{
DEKOMPOSISI GRAF MATAHARI $\left(C_{n} \odot \overline{\left(K_{1}\right)}\right)$
}

\author{
Putri Rizqi Musthofa $^{1}$, Yemi Kuswardi ${ }^{2}$ \\ ${ }^{1,2}$ Prodi Pendidikan Matematika, FKIP, UNS
}

\begin{abstract}
Graph theory is a branch of mathematics that facilitates problem solving. There are a lot of researches which concern on this issue. Various kinds of terms are introduced, one of them is graph decomposition. Graph decomposition is sub graphs collection of non-empty $\mathrm{G}$ graph $\{\mathrm{Hi}\}$ until $\mathrm{Hi}=\langle\mathrm{Ei}\rangle$ for non-empty sub graph Ei of $\mathrm{E}(\mathrm{G})$, where $\{\mathrm{Ei}\}$ is a partition of $\mathrm{E}(\mathrm{G})$. Sub graph $\mathrm{Hi}$ in decomposition $\mathrm{G}$ do not contain of isolated points. If $\{\mathrm{Hi}\}$ is a decomposition of $\mathrm{G}$, it is denoted by $\boldsymbol{G}=$ $\boldsymbol{H}_{\mathbf{1}} \oplus \boldsymbol{H}_{\mathbf{2}} \oplus \boldsymbol{H}_{\mathbf{3}} \ldots \oplus \boldsymbol{H}_{\boldsymbol{i}}$. The discussion of graph decomposition can be developed in graph decomposition through various types. One of the types is decomposition of sun graphs. Sun graph is a graph formed from a circle $\mathrm{Cn}$ in which each vertex on a circle graph is given one additional vertex with a degree. So, each vertex in sun graph has 3 degrees, except the edge of cortex which only have 1 degree. The sun graph is the result of corona between two graphs, namely a circular graph with $\mathrm{n}$ vertex and complement of a complete graph with 1 number of vertex $\left(\overline{\boldsymbol{K}_{1}}\right)$. The sun graph is denoted by $\boldsymbol{C}_{\boldsymbol{n}} \odot \overline{\boldsymbol{K}_{\mathbf{1}}}$ where $\mathrm{n}$ is the number of vertex in circle graph. If the vertex naming refers to one vertex (with clockwise rules) and additional vertex naming connected to a circle vertex graph (vi), where the additional vertex has a degree of one, then the rule of naming is $\boldsymbol{v}_{\boldsymbol{i}+\boldsymbol{n}}$ and sun graph is partitioned into a sub graph $\mathrm{H} \_\mathrm{i}=\langle\mathrm{Ei}$ $>$ in the form of $\mathrm{K}_{2}$ where $\mathrm{i} \neq \mathrm{j}$ so that $\mathrm{H} \_\mathrm{i} \cap \mathrm{H} \_\mathrm{j}=\emptyset$, for $\mathrm{i}=1,2,3, \ldots, \mathrm{n}$ with sub graph $\boldsymbol{H}_{\boldsymbol{i}}=\left\langle\left\{\left(\boldsymbol{v}_{\boldsymbol{i}}, \boldsymbol{v}_{\boldsymbol{i}+\boldsymbol{n}}\right),\left(\boldsymbol{v}_{\boldsymbol{i}+\mathbf{1}}, \boldsymbol{v}_{\boldsymbol{i}+2}\right)\right\}\right\rangle$. If every $\left.\mathrm{i}+1, \mathrm{i}+2\right\rangle \mathrm{n}$ has an implicit +1 and $\mathrm{i}+2$ will be expressed as an integers $1,2,3, \ldots, \mathrm{n}(\bmod \mathrm{n})$, then the sun graph is $2 \mathrm{~K}_{2-}$ decomposition. So, for sun graph $\left(\boldsymbol{C}_{\boldsymbol{n}} \odot \overline{\boldsymbol{K}_{\mathbf{1}}}\right) \mathrm{n} \geq 3$ is $2 \mathrm{~K} 2$-decomposition.
\end{abstract}

Keywords:Decomposition, Sun Graph.

\section{PENDAHULUAN}

Teori graf merupakan salah satu cabang ilmu matematika yang banyak digunakan untuk mempermudah suatu penyelesaian masalah. Teori graf merupakan pokok bahasan yang muncul pertama kali pada tahun 1736, yakni ketika Leonhard Euler mencoba untuk mencari solusi dari permasalahan yang sangat terkenal yaitu Jembatan Konigsberg.

Teori ini sudah mengalami berbagai pengembangan baik dari sisi teori maupun terapannya. Beberapa masalah dalam dunia nyata dapat diselesaikan menggunakan konsep-konsep dalam teori graf, misal masalah jaringan di bidang ilmu komputer, riset operasi, komunikasi, dan ilmu-ilmu sosial atau ilmu pengetahuan alam (Chartrand (1977), Deo (1980)).

Pada teori graf, kita mengenal bahwa sebuah graf $\mathrm{G}$ dinyatakan sebagai pasangan terurut dua himpunan, yaitu himpunan hingga tak kosong $\mathrm{V}(\mathrm{G})$ yang elemen - elemennya disebut titik dan himpunan berhingga yang mungkin kosong $E(G)$ yang elemen elemennya disebut sisi sedemikian hingga setiap elemen dalam $E(G)$ merupakan pasangan tak berurutan dari titik - titik di $V(G)$. $(G)$ disebut himpunan titik dari graf $\mathrm{G}$ dan $(G)$ disebut himpunan sisi dari graf $G$ (Suryanto, 1986). Dalam teori ini, ada beberapa bentuk 
graf antara lain yang banyak dikenal adalah graf bentuk bintang (star), lingkaran (cycle), lintasan (path), roda (wheel), gir (gear), helm, firecracker, banana tree, kipas (fan), dan lain-lain (Wallis, 2001).

Pada teori ini pula, diperkenalkan istilah dekomposisi untuk sebuah graf. Dekomposisi graf merupakan koleksi subgraf dari graf $G$ yang tak kosong $\left\{H_{i}\right\}$ sedemikian hingga $H_{i}=\left\langle E_{i}\right\rangle$ untuk suatu subgraf tak kosong $E_{i}$ dari $E(G)$, dimana $\left\{E_{i}\right\}$ adalah partisi dari $E(G)$. Subgraf $H_{i}$ pada dekomposisi $G$ tidak memuat titik terisolasi. Jika $\left\{H_{i}\right\}$ adalah sebuah dekomposisi dari $\mathrm{G}$, maka dinotasikan dengan $G=H_{1} \oplus H_{2} \oplus H_{3} \ldots . \oplus H_{i}$. Penelitian tentang dekomposisi telah dibahas dibeberapa artikel maupun skripsi. Salah satu artikel yang ditulis oleh Nur Rahmawati pada tahun 2014 dengan judul "Dekomposisi Graf Sikel, Graf Roda, Graf Gir dan Graf Persahabatan" menerangkan bagaimana cara mencari dekomposisi dari empat graf yang dipilih tersebut dan teorema apa saja yang berlaku pada masing-masing graf yang didekomposisi. Pembahasan tentang dekomposisi graf masih dapat dilanjutkan pada dekomposisi graf yang lain seperti graf matahari. Graf matahari merupakan graf yang dibentuk dari suatu graf lingkaran $C_{n}$ dimana setiap vertex pada graf lingkaran tersebut diberi tambahan satu vertex berderajat satu sedemikian sehingga setiap vertex pada graf matahari memiliki derajat 3 , kecuali pada vertex ujung-ujungnya yang memiliki derajat 1 . Graf matahari sendiri adalah hasil produk korona antara dua graf, yaitu graf lingkaran dengan $n$ vertex dan komplemen dari graf lengkap dengan jumlah vertex satu $\left(\overline{K_{1}}\right)$. Graf matahari dinotasikan dengan $C_{n} \odot \overline{K_{1}}$, dengan $n$ menyatakan banyaknya vertex pada graf lingkaran. Berdasarkan hal tersebut, maka pada makalah ini akan dibahas mengenai “Dekomposisi Graf Matahari $\left(C_{n} \odot \overline{K_{1}}\right)$ ".

\section{METODE PENELITIAN}

\section{Definisi 1}

Sebuah graf $G$ didefinisikan sebagai pasangan terurut dua himpunan, yaitu himpunan hingga tak kosong $\mathrm{V}(\mathrm{G})$ yang elemen - elemennya disebut titik atau simpul(vertex) dan himpunan berhingga yang mungkin kosong $E(G)$ yang elemen - elemennya disebut sisi (edge) sedemikian hingga setiap elemen dalam $E(G)$ merupakan pasangan tak berurutan dari titik - titik di $V(G)$. Vertex adalah sekumpulan titik, representasi dari suatu graf yang dihubungkan dengan sekumpulan garis (edge). Sedangkan edge adalah segmen garis yang menghubungkan dua vertex.Sisi $\mathrm{e}=(\mathrm{u}, \mathrm{v})$ dikatakan menghubungkan titik u dan v. $V(G)$ disebut himpunan titik dari graf $G$ dan $E(G)$ disebut himpunan sisi dari graf $G$.

(Suryanto. 1986:1.3) 


\section{Definisi 2}

Sebuah graf $H$ didefinisikan sebagai graf bagian atau subgraf dari graf $G(H \subseteq G)$ jika dan hanya jika tiap-tiap titik $V(H)$ merupakan anggota himpunan $V(G)$ dan tiap-tiap sisi $\mathrm{E}(\mathrm{H})$ merupakan anggota himpunan $\mathrm{E}(\mathrm{G})$.

(Rahmawati, 2014: 65)

\section{Definisi 3}

Jika $H \subseteq G$ dan $V(H)=V(G)$ maka $\mathrm{H}$ disebut graf bagian rentang (spanning subgraf) dari graf $G$.

(Hasmawati, 2015:17)

\section{Definisi 4}

Misalkan $G$ adalah suatu graf dan $v$ titik di $G$. Derajat titik $v$ di $G$, ditulis $\operatorname{der}_{G}(v)$ (degree) adalah banyaknya sisi di $G$ yang terkait langsung dengan $v$. Jadi $\operatorname{der}_{G}(v)$ adalah banyaknya titik yang terhubung langsung dengan $v$, sedangkan titik yang berderajat satu disebut titik ujung.

(Lipschutz dan Lipson, 2002:7)

\section{Definisi 5}

Misalkan $G$ adalah suatu graf dimana setiap vertex berderajat $k$, maka $G$ dikatakan graf beraturan-k.

(Lipschutz dan Lipson, 2002:31)

\section{Definisi 6}

Sebuah graf $\mathrm{F}$ dikatakan komplemen graf $\mathrm{G}$, jika $V(F)=V(G)$ dan $u v \in E(F)$ jika dan hanya jika $u v \notin E(G)$. Komplemen dari graf $\mathrm{G}$ dinotasikan menjadi $\bar{G}$.

(Hasmawati, 2015:13).

\section{Definisi 7}

Graf sederhana adalah graf yang tidak mempunyailoop dan sisi rangkap. Sisi rangkap dari suatu graf adalah jika dua titik yang dihubungkan oleh lebih dari satu sisi. Sedangkan yang disebut dengan loop adalah suatu sisi yang menghubungkan suatu titik dengan dirinya sendiri.

(Fatkhiyah, 2010: 10).

\section{Definisi 8}

Graf komplit adalah graf dengan setiap pasang titik yang berbeda dihubungkan oleh satu sisi. komplit dengan $n$ titik dinotasikan sebagai $K_{n}$. 


\section{Definisi 9}

Untuk suatu bilangan bulat $n \geq 1$, lintasan $P_{n}$ adalah suatu graf yang memiliki order $n$ dan ukuran $n-1$ yang vertexnya dapat dinotasikan dengan $v_{1}, v_{2}, \ldots, v_{n}$ dan sisinya dengan $e_{i}=\left(v_{i} v_{i+1}\right)$ untuk setiap $i=1,2, \ldots, n-1$.

(Addinnitya, 2012: 8).

\section{Definisi 10}

Graf sikel (Cycle Graph) merupakan graf sederhana yang setiap titiknya berderajat dua. Graf sikel dengan $n$ titik dilambangkan dengan $C_{n}$. Banyak sisi pada sebuah graf sikel yang terdiri dari $n$ buah titik adalah $n$.

(Rahmawati, 2014: 65)

\section{Definisi 11}

Graf matahari $\left(C_{n} \odot \overline{K_{1}}\right)$ merupakan graf yang dibentuk dari suatu graf lingkaran $C_{n}$ dimana setiap vertex pada graf lingkaran tersebut diberi tambahan satu vertex berderajat satu sedemikian sehingga setiap vertex pada graf matahari memiliki derajat 3 , kecuali pada vertex ujung-ujungnya yang memiliki derajat 1 . Graf matahari sendiri adalah hasil produk korona antara dua graf, yaitu graf lingkaran dengan $n$ vertex dan komplemen dari graf lengkap dengan jumlah vertex satu $\left(\overline{K_{1}}\right)$. Graf matahari dinotasikan dengan $C_{n} \odot \overline{K_{1}}$, dengan $n$ menyatakan banyaknya vertex pada graf lingkaran.

Pada makalah ini, pemberian nama vertex pada graf matahari dimulai dari salah satu vertex dengan aturan searah jarum jam. Dan untuk penamaan vertex tambahan yang terhubung dengan suatu vertex graf lingkaran $\left(v_{i}\right)$ dimana vertex tambahan tersebut berderajat satu, maka aturan penamaan tersebut berlaku $v_{i+n}$.(Addinnitya, 2012: 10).Contoh:

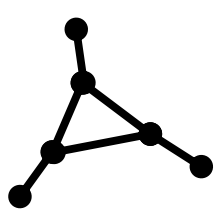

$C_{3} \odot \overline{K_{1}}$

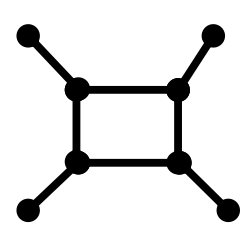

$C_{4} \odot \overline{K_{1}}$

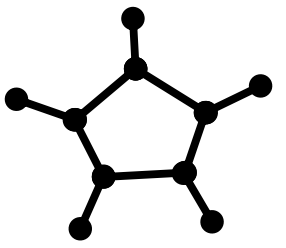

$C_{5} \odot \overline{K_{1}}$

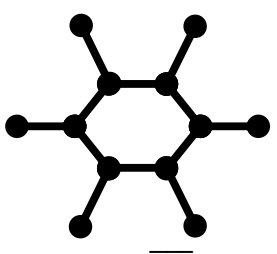

$C_{6} \odot \overline{K_{1}}$

\section{Gambar 1. Graf Matahari}

\section{Definisi 12}

Operasi korona dari dua graf, misalnya graf $G$ dan $H$ didefinisikan sebagai graf yang diperoleh dengan mengambil sebuah graf $G$ dan graf $\mathrm{H}$ yang diduplikasi sebanyak $|V(G)|$ 
yaitu $H_{i}, i=1,2, \ldots,|V(G)|$, kemudian menghubungkan titik ke $-i$ dari $G$ ke setiap titik $\operatorname{di} H_{i}$.

(Mursyidah dan Rahmawati, 2017: 1)

\section{Definisi 13}

Titik terisolasi (isolated vertex) adalah titik yang tidak satupun berhubungan langsung dengan titik - titik yang lainnya.

(Rahmawati, 2014: 65)

\section{Definisi 14}

Dua graf $G_{1}$ dan $G_{2}$ dikatakan isomorfik jika ada korespondensi satu-satu antara titik-titik $G_{1}$ dan titik-titik dari $G_{2}$ sedemikian hingga banyaknya rusuk yang menghubungkan sebarang dua titik dari $G_{1}$ sama dengan banyaknya rusuk yang menghubungkan kedua titik yang bersesuaian dari $G_{2}$.

(Suryanto. 1986:1.20)

\section{Definisi 15}

Graf $G$ dikatakan dapat difaktorkan ke dalam faktor-faktor $G_{1}, G_{2}, \ldots, G_{t}$. jika faktorfaktor tersebut merupakan sisi yang saling lepas untuk setiap pasangan sisi dan $\mathrm{U}_{i=1}^{t} \mathrm{E}\left(\mathrm{G}_{\mathrm{i}}\right)=\mathrm{E}(\mathrm{G})$.

Jika $G$ difaktorkan kedalam $G_{1}, G_{2}, \ldots, G_{t}$ maka dituliskan dengan $G=G_{1} \oplus$ $G_{2} \oplus \ldots \oplus G_{t}$ dan disebut sebagai faktorisasi $G$.

Jika terdapat faktorisasi dari graf $G$ sedemikian hingga untuk setiap faktor adalah k-faktor ( k-faktor adalah graf bagian rentang beraturan-k), maka $G$ dikatakan k-faktor. Jika $G$ adalah graf k-faktor, maka $G$ adalah graf beraturan-r untuk bilangan bulat $\mathrm{r}$ yang merupakan kelipatan $\mathrm{k}$.

Jika graf $G$ dapat difaktorkan kedalam $G_{1}, G_{2}, \ldots, G_{t}$ di mana $G_{i}=H$ untuk sebuah graf $H$ untuk setiap bilangan bulat $\mathrm{i}(1 \leq \mathrm{i} \leq \mathrm{t})$, maka kita katakan bahwa $G$ adalah terfaktorisasi $-H$ dan $G$ memiliki faktor yang isomorfik dengan $H$.

Contoh:

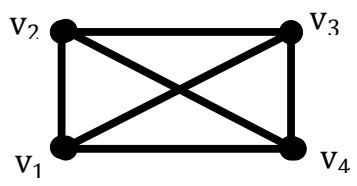

Gambar 2. Graf $\mathbf{K}_{4}$

Bentuk faktorisasi graf $\mathrm{K}_{4}$ adalah sebagai berikut: 


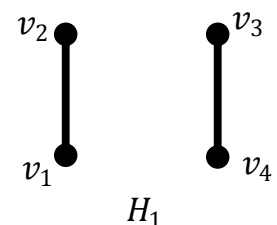

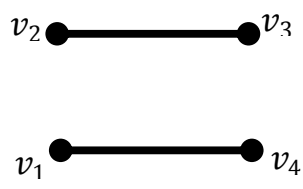

$\mathrm{H}_{2}$

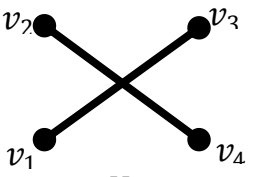

$\mathrm{H}_{3}$

Gambar 3. Bentuk faktorisasi graf komplit $G$

(Rahmawati, 2014: 65)

\section{Definisi 16}

Dekomposisi graf $\mathrm{G}$ adalah koleksi subgraf dari $G$ tak $\operatorname{kosong}\left\{H_{i}\right\}$ sedemikian hingga $H_{i}$ $=\left\langle E_{i}\right\rangle$ untuk suatu subgraf tak kosong $E_{i}$ dari $E(G)$,dimana $\left\{E_{i}\right\}$ adalah partisi dari $E$ $(G)$.subgraf $H_{i}$ pada dekomposisi G tidak memuat titik terisolasi. Jika $\left\{H_{i}\right\}$ adalah sebuah dekomposisi dari G, maka dinotasikan dengan $G=H_{1} \oplus H_{2} \oplus H_{3} \ldots . \oplus H_{i}$ sama seperti pada faktorisasi dan $G$ didekomposisikan ke dalam subgraf $H_{1}, H_{2} \ldots ., H_{t}$ dimana $\left|\left\{H_{i}\right\}\right|=t$. Dengan kata lain, jika $G=H_{1} \oplus H_{2} \oplus H_{3} \ldots . \oplus H_{i}$ merupakan dekompisisi dari graf G. Jika $\left\{H_{i}\right\}$ adalah dekomposisi graf $\mathrm{G}$ dimana untuk sebuah graf $\mathrm{H}$ dan setiap $i$ berlaku $H_{i}=H$ untuk sebuah garf $H$ dan untuk setiap $i$, maka $\mathrm{G}$ dikatakan $\mathrm{H}$ dekomposisi. Jika $G$ merupakan graf $H$-dekomposisi, maka dinotasikan $H \mid G$ sehingga $H$ dapat dikatakan pembagi banyaknya sisi di G dan G merupakan kelipatan dari $H$. Dengan kata lain untuk setiap graf (tak kosong) merupakan $K_{2}$-dekomposisi.

\section{Contoh :}

Perhatikan graf $\mathrm{G}$ berikut ini:

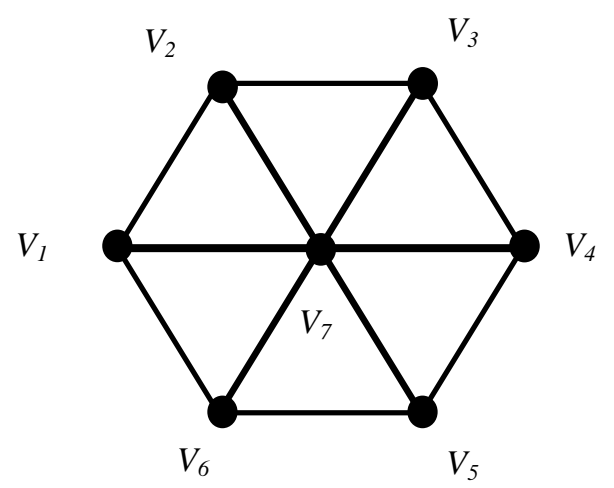

Gambar 4. Graf G

Partisi sisi-sisi dari graf $\mathrm{G}$ tersebut adalah: 


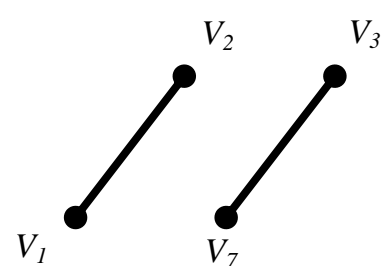

$H_{l}$

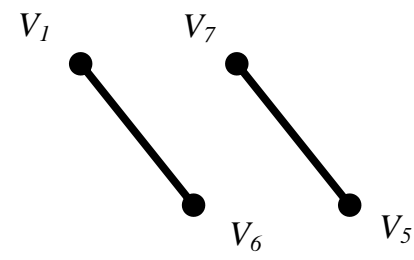

$\mathrm{H}_{4}$

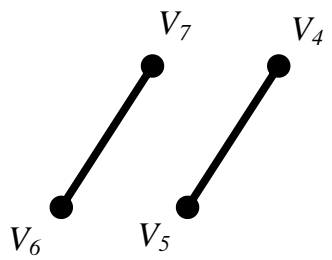

$H$

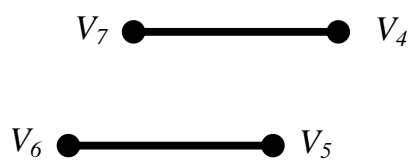

$\mathrm{H}_{5}$

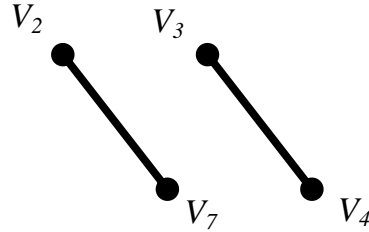

$\mathrm{H}_{3}$

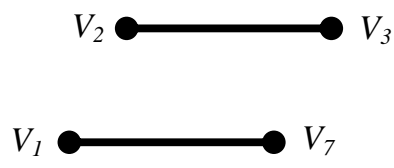

$H_{6}$

\section{Gambar 5. Partisi Sisi-Sisi Graf G}

Dari Gambar 5 terlihat bahwa diperoleh 6 partisi dari $\mathrm{E}(\mathrm{G})$, yaitu $H_{1}, H_{2}, H_{3}, H_{4}, H_{5}, H_{6}$ dengan masing-masing partisi terdiri dari 2 sisi. Karena $G=$ $H_{1} \oplus H \oplus H_{3} \oplus H_{4} \oplus H_{5} \oplus H_{6}$ maka G dikatakan dapat didekomposisikan.

Sebuah graf $\mathrm{G}$ didekomposisikan ke dalam subgraf $H_{1}, H_{2}, H_{3}, H_{4}, \ldots, H_{n}$ jika ada dua subgraf $\mathrm{H}_{1}$ dan $\mathrm{H}_{i}$ yang tidak memiliki sisi yang sama dan dimana setiap subgrafnya isomorfis serta penjumlahan semua subgraf $\mathrm{H}_{\mathrm{i}}$ adalah graf $\mathrm{G}$.

Suatu graf terhubung beraturan-2 disebut graf lingkaran (cycle graph). Graf lingkaran dengan $n$ vertex, $n \geq 3$ dinyatakan sebagai $C_{n}$. Dalam graf lingkaran $C_{n}$ berlaku $\left|V\left(C_{n}\right)\right|=\left|E\left(C_{n}\right)\right|$.

(Rahmawati, 2014: 66)

\section{HASIL DAN PEMBAHASAN}

Sebuah graf $G$ di dekomposisikan ke dalam subgraf $H_{1}, H_{2}, \ldots, H_{n}$ jika ada dua subgraf $H_{i}$ dan $H_{j}$ yang tidak mempunyai sisi-sisi yang sama dan dimana setiap subgrafnya isomorfis serta penjumlahan semua subgraf $H_{i}$ adalah graf $G$.

Misalkan diambil graf matahari $C_{n} \odot \overline{K_{1}}$ dengan $3 \leq n \leq 9$, kemudian graf matahari $C_{n} \odot \overline{K_{1}}$ dipartisi menjadi subgraf $H_{i}$ berupa $K_{2}$, maka dekomposisi dari graf matahari $C_{n} \odot \overline{K_{1}}$ dapat dilihat pada tabel berikut ini. 
Tabel 1 Dekomposisi dari graf Matahari $C_{n} \odot \overline{K_{1}}$

\begin{tabular}{|c|c|c|c|}
\hline $\begin{array}{l}\text { Graf } \\
\text { Matahar } \\
\text { i }\end{array}$ & Dekomposisi & $\begin{array}{c}\mathrm{H}- \\
\text { dekomposisi }\end{array}$ & Banyaknyatitik dan sisi \\
\hline$\overline{C_{3} \odot \overline{K_{1}}}$ & $\begin{array}{c}C_{3} \odot \overline{K_{1}}=H_{1} \oplus H_{2} \oplus H_{3} \\
\text { (3 partisi) }\end{array}$ & $H_{i}=2 K_{2}$ & $\begin{array}{l}\left|V\left(H_{1}\right)\right|=\left|V\left(H_{2}\right)\right|=\left|V\left(H_{3}\right)\right|=4 \\
\left|E\left(H_{1}\right)\right|=\left|E\left(H_{2}\right)\right|=\left|E\left(H_{3}\right)\right|=2\end{array}$ \\
\hline$C_{4} \odot \overline{K_{1}}$ & $\begin{array}{c}C_{4} \odot \overline{K_{1}}=H_{1} \oplus H_{2} \\
\oplus H_{3} \oplus H_{4} \\
(4 \text { partisi) }\end{array}$ & $H_{i}=2 K_{2}$ & $\begin{array}{c}\left|V\left(H_{1}\right)\right|=\left|V\left(H_{2}\right)\right|=\left|V\left(H_{3}\right)\right| \\
=\left|V\left(H_{4}\right)\right|=4 \\
\left|E\left(H_{1}\right)\right|=\left|E\left(H_{2}\right)\right|=\left|E\left(H_{3}\right)\right| \\
=\left|E\left(H_{4}\right)\right|=2\end{array}$ \\
\hline$C_{5} \odot \overline{K_{1}}$ & $\begin{array}{c}C_{5} \odot \overline{K_{1}}=H_{1} \oplus H_{2} \oplus H_{3} \\
\bigoplus H_{4} \oplus H_{5} \\
\text { (5 partisi) }\end{array}$ & $H_{i}=2 K_{2}$ & $\begin{array}{c}\left|V\left(H_{1}\right)\right|=\left|V\left(H_{2}\right)\right|=\left|V\left(H_{3}\right)\right| \\
=\left|V\left(H_{4}\right)\right|=\left|V\left(H_{5}\right)\right|=4 \\
\left|E\left(H_{1}\right)\right|=\left|E\left(H_{2}\right)\right|=\left|E\left(H_{3}\right)\right| \\
=\left|E\left(H_{4}\right)\right|=\left|E\left(H_{5}\right)\right|=2\end{array}$ \\
\hline$C_{6} \odot \overline{K_{1}}$ & $\begin{array}{c}C_{6} \odot \overline{K_{1}}=H_{1} \oplus H_{2} \oplus H_{3} \\
\oplus H_{4} \oplus H_{5} \oplus H_{6} \\
(6 \text { partisi })\end{array}$ & $H_{i}=2 K_{2}$ & $\begin{array}{c}\left|V\left(H_{1}\right)\right|=\left|V\left(H_{2}\right)\right|=\left|V\left(H_{3}\right)\right| \\
=\left|V\left(H_{4}\right)\right|=\left|V\left(H_{5}\right)\right|=\left|V\left(H_{6}\right)\right| \\
=4 \\
\left|E\left(H_{1}\right)\right|=\left|E\left(H_{2}\right)\right|=\left|E\left(H_{3}\right)\right| \\
=\left|E\left(H_{4}\right)\right|=\left|E\left(H_{5}\right)\right|=\left|E\left(H_{6}\right)\right| \\
=2\end{array}$ \\
\hline$C_{7} \odot \overline{K_{1}}$ & $\begin{array}{c}C_{7} \odot \overline{K_{1}}=H_{1} \oplus H_{2} \oplus H_{3} \\
\oplus H_{4} \oplus H_{5} \oplus H_{6} \oplus H_{7} \\
\text { (7 partisi) }\end{array}$ & $H_{i}=2 K_{2}$ & $\begin{array}{c}\left|V\left(H_{1}\right)\right|=\left|V\left(H_{2}\right)\right|=\left|V\left(H_{3}\right)\right| \\
=\left|V\left(H_{4}\right)\right|=\left|V\left(H_{5}\right)\right|=\left|V\left(H_{6}\right)\right| \\
=\left|V\left(H_{7}\right)\right|=4 \\
\left|E\left(H_{1}\right)\right|=\left|E\left(H_{2}\right)\right|=\left|E\left(H_{3}\right)\right| \\
=\left|E\left(H_{4}\right)\right|=\left|E\left(H_{5}\right)\right|=\left|E\left(H_{6}\right)\right| \\
=\left|E\left(H_{7}\right)\right|=2\end{array}$ \\
\hline$\overline{C_{8} \odot \overline{K_{1}}}$ & $\begin{array}{c}C_{8} \odot \overline{K_{1}}=H_{1} \oplus H_{2} \oplus H_{3} \\
\oplus H_{4} \oplus H_{5} \oplus H_{6} \oplus H_{7} \oplus H_{8} \\
\text { (8 partisi) }\end{array}$ & $H_{i}=2 K_{2}$ & $\begin{array}{c}\left|V\left(H_{1}\right)\right|=\left|V\left(H_{2}\right)\right|=\left|V\left(H_{3}\right)\right| \\
=\left|V\left(H_{4}\right)\right|=\left|V\left(H_{5}\right)\right|=\left|V\left(H_{6}\right)\right| \\
=\left|V\left(H_{7}\right)\right|=\left|V\left(H_{8}\right)\right|=4 \\
\left|E\left(H_{1}\right)\right|=\left|E\left(H_{2}\right)\right|=\left|E\left(H_{3}\right)\right| \\
=\left|E\left(H_{4}\right)\right|=\left|E\left(H_{5}\right)\right|=\left|E\left(H_{6}\right)\right| \\
=\left|E\left(H_{7}\right)\right|=\left|E\left(H_{8}\right)\right|=2\end{array}$ \\
\hline$C_{9} \odot \overline{K_{1}}$ & $\begin{array}{c}C_{9} \odot \overline{K_{1}}=H_{1} \oplus H_{2} \oplus H_{3} \\
\bigoplus H_{4} \oplus H_{5} \oplus H_{6} \oplus H_{7} \\
\oplus H_{8} \oplus H_{9} \\
(9 \text { partisi) }\end{array}$ & $H_{i}=2 K_{2}$ & $\begin{array}{c}\left|V\left(H_{1}\right)\right|=\left|V\left(H_{2}\right)\right|=\left|V\left(H_{3}\right)\right| \\
=\left|V\left(H_{4}\right)\right|=\left|V\left(H_{5}\right)\right|=\left|V\left(H_{6}\right)\right| \\
=\left|V\left(H_{7}\right)\right|=\left|V\left(H_{8}\right)\right|=\left|V\left(H_{9}\right)\right| \\
=4 \\
\left|E\left(H_{1}\right)\right|=\left|E\left(H_{2}\right)\right|=\left|E\left(H_{3}\right)\right| \\
=\left|E\left(H_{4}\right)\right|=\left|E\left(H_{5}\right)\right|=\left|E\left(H_{6}\right)\right| \\
=\left|E\left(H_{7}\right)\right|=\left|E\left(H_{8}\right)\right|=\left|E\left(H_{9}\right)\right| \\
=2\end{array}$ \\
\hline$\overline{C_{n} \odot \overline{K_{1}}}$ & $\begin{array}{c}C_{n} \odot \overline{K_{1}}=H_{1} \oplus H_{2} \\
\oplus \ldots \oplus H_{n} \\
(n \text { partisi })\end{array}$ & $H_{i}=2 K_{2}$ & $\begin{array}{c}\left|V\left(H_{1}\right)\right|=\left|V\left(H_{2}\right)\right|=\cdots=\left|V\left(H_{n}\right)\right| \\
=4 \\
\left|E\left(H_{1}\right)\right|=\left|E\left(H_{2}\right)\right|=\cdots=\left|E\left(H_{n}\right)\right| \\
=2\end{array}$ \\
\hline
\end{tabular}

Berdasarkan Tabel 1 diatas, maka diperoleh teorema sebagai berikut:

\section{Teorema}

Graf Matahari $C_{n} \odot \overline{K_{1}}, n \geq 3$ merupakan $2 K_{2}$-dekomposisi.

Bukti:

Ambil sebarang graf matahari $C_{n} \odot \overline{K_{1}}$ 
Misal, $V\left(C_{n} \odot \overline{K_{1}}\right)=\left\{v_{1}, v_{2}, v_{3}, \ldots, v_{n}, v_{n+1}, \ldots, v_{2 n}\right)$ dan

$E\left(C_{n} \odot \overline{K_{1}}\right)=\left\{e_{1}, e_{2}, e_{3}, \ldots, e_{n}, e_{n+1}, \ldots e_{2 n}\right)$

Partisi graf matahari $C_{n} \odot \overline{K_{1}}$ menjadi subgraf $H_{i}=\left\langle E_{i}\right\rangle$ yang berupa $K_{2}$ dimana $i \neq j$ maka $H_{i} \cap H_{j}=\varnothing$.

Misalkan $C_{n} \odot \overline{K_{1}}=H_{1} \oplus H_{2} \oplus H_{3} \ldots \ldots \oplus H_{n}$.

Partisi graf matahari $C_{n} \odot \overline{K_{1}}$ sebagai berikut:

Untuk $i=1,2,3, \ldots, n$.

Subgraf $H_{i}=\left\langle\left\{\left(v_{i}, v_{i+n}\right),\left(v_{i+1}, v_{i+2}\right)\right\}\right\rangle$, dimana setiap $i+1, i+2>n$ maka $i+1$ dan $i+2$ dinyatakan sebagai bilangan bulat $1,2,3, \ldots, n(\bmod n)$.

Untuk menunjukkan setiap subgraf saling lepas dimana $i \neq j$ maka $H_{i} \cap H_{j}=\emptyset$. Andaikan $H_{i} \cap H_{j}=\emptyset$, maka $\exists e_{k} \in H_{i} \cap H_{j}, k \in \mathbb{N}$. Hal ini berarti bahwa $e_{k} \in H_{i}$ dan $e_{k} \in H_{j}$. Jika $e_{k} \in H_{i}$ berdasarkan definisi maka $e_{k}=\left(v_{i}, v_{i+n}\right)$ atau $\left(v_{i+1}, v_{i+2}\right)$ dan $e_{k} \in H_{j}$ berdasarkan definisi maka $e_{k}=\left(v_{j}, v_{j+n}\right)$ atau $\left(v_{j+1}, v_{j+2}\right)$.

Akibatnya $\left(v_{i}, v_{i+n}\right)=\left(v_{j}, v_{j+n}\right)$ dan $\left(v_{i+1}, v_{i+2}\right)=\left(v_{j+1}, v_{j+2}\right)$ sedemikian sehingga $i=j$. Jika $i=j$ maka setiap $i+1, i+2>n$ dinyatakan sebagai bilangan bulat $1,2,3, \ldots,(n-1)(\bmod n)$ sehingga tidak ada sisi yang sama pada setiap subgraf. Oleh karena itu diperoleh $i \neq j, H_{i} \cap H_{j}=\emptyset$ kontradiksi dengan pengandaian. Dengan demikian untuk setiap $i=1,2,3, \ldots, n$, dan $C_{n} \odot \overline{K_{1}}=H_{1} \oplus H_{2} \oplus H_{3} \ldots . \oplus H_{n}$ maka $C_{n} \odot \overline{K_{1}}$ merupakan $2 K_{2}$-dekomposisi.

Contoh:

Diberikan graf matahari $C_{n} \odot \overline{K_{1}} ; n=4$

Misal $G=C_{4} \odot \overline{K_{1}}$

Dapat digambarkan sebagai berikut:

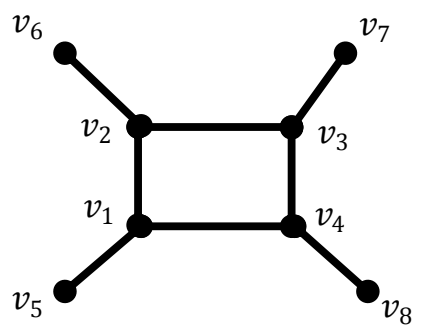

Gambar 6. Graf $G=C_{4} \odot \overline{K_{1}}$

Titik - titik dari $G$ adalah $\left\{v_{1}, v_{2}, v_{3}, v_{4}, v_{5}, v_{6}, v_{7}, v_{8}\right\}$ 
Untuk $i=1,2,3,4$ maka $H_{1}=\left\langle\left\{\left(v_{1}, v_{5}\right),\left(v_{2}, v_{3}\right)\right\}\right\rangle H_{2}=\left\langle\left\{\left(v_{2}, v_{6}\right),\left(v_{3}, v_{4}\right)\right\}\right\rangle$ karena $i+2>n$, maka untuk titik $v_{5}$ yaitu bilangan 5 diambil sebagai $1(\bmod 4)$ sehingga $H_{3}=\left\langle\left\{\left(v_{3}, v_{7}\right),\left(v_{4}, v_{1}\right)\right\}\right\rangle$

Dengan cara yang sama maka akan diperoleh : $H_{4}=\left\langle\left\{\left(v_{4}, v_{8}\right),\left(v_{1}, v_{2}\right)\right\}\right\rangle$

Sehingga dekomposisi dari $G=C_{4} \odot \overline{K_{1}}$
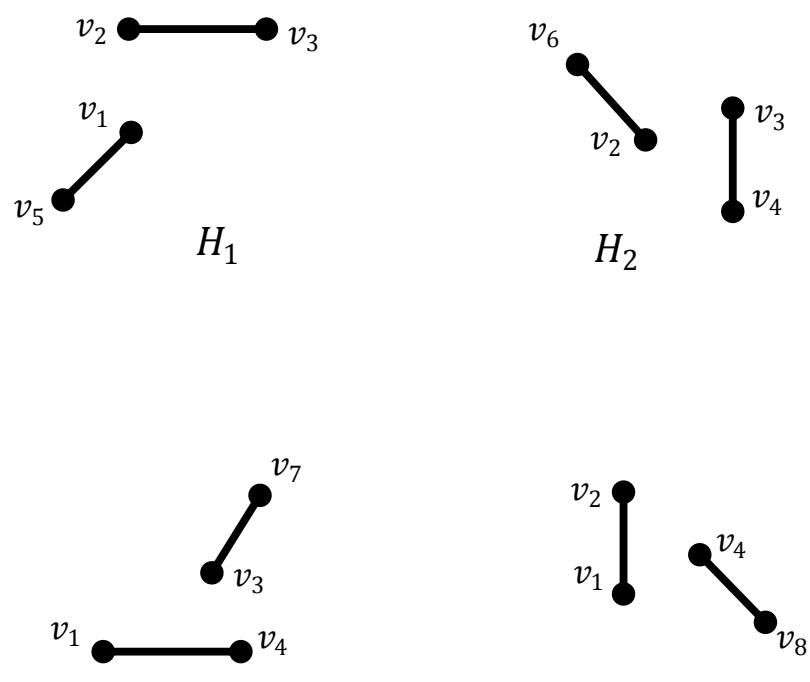

$\mathrm{H}_{3}$

$\mathrm{H}_{4}$

Gambar 7. Dekomposisi graf $C_{4} \odot \overline{K_{1}}$

Karena $G=H_{1} \oplus H_{2} \oplus H_{3} \oplus H_{4}$ dimana setiap subgraf $H_{i}$ didekomposisi sebanyak 2 yang berupa $K_{2}$. Sehingga $C_{4} \odot \overline{K_{1}}$ merupakan $2 K_{2}$-dekomposisi.

\section{SIMPULAN DAN SARAN}

Berdasarkan pada pembahasan pada bab sebelumnya, diambil kesimpulan sebagai berikut:

1. Graf matahari $\left(C_{n} \odot \overline{K_{1}}\right)$ merupakan graf yang dibentuk dari suatu graf lingkaran $C_{n}$ dimana setiap vertex pada graf lingkaran tersebut diberi tambahan satu vertex berderajat satu sedemikian sehingga setiap vertex pada graf matahari memiliki derajat 3 , kecuali pada vertex ujung-ujungnya yang memiliki derajat 1 . Jika penamaan vertex mengacu pada salah satu vertex, dengan aturan searah jarum jam, dan penamaan vertex tambahan yang terhubung dengan suatu vertex graf lingkaran $\left(v_{i}\right)$ dimana vertex tambahan tersebut berderajat satu, maka aturan penamaan tersebut berlaku $v_{i+n}$, dan graf matahari dipartisi menjadi subgraf $H_{i}=\left\langle E_{i}\right\rangle$ berupa $K_{2}$ dimana $i \neq j$ sehingga $H_{i} \cap H_{j}=\varnothing \quad$ untuk $i=1,2,3, \ldots, n$ dengan subgraf $H_{i}=\left\langle\left\{\left(v_{i}, v_{i+n}\right),\left(v_{i+1}, v_{i+2}\right)\right\}\right\rangle$ apabila untuk setiap $i+1, i+2>n$ berakibat $i+1$ 
dan $i+2$ akan dinyatakan sebagai bilangan bulat $1,2,3, \ldots, n(\bmod n)$, maka graf matahari merupakan $2 K_{2}$-dekomposisi.

2. Teorema yang berlaku pada Graf Matahari $C_{n} \odot \overline{K_{1}}$ yang dipartisi menjadi subgraf $H_{i}$ berupa $2 K_{2}$ untuk setiap $i=1,2,3, \ldots, n$, dan $C_{n} \odot \overline{K_{1}}=H_{1} \oplus H_{2} \oplus H_{3} \ldots \oplus H_{n}$ maka $C_{n} \odot \overline{K_{1}}$ merupakan $2 K_{2}$-dekomposisi.

\section{DAFTAR PUSTAKA}

Addinnitya, Arief. (2012). Pelabelan Jumlah Eksklusif pada Graf Matahari, Graf Korona, dan Graf Hairycycle dengan Banyak Simpul Lingkaran Genap. Hlm. 810. LIB UI.

Asmiati. (2016). Graf dan Aplikasinya pada Jarak Terpendek. Yogyakarta: Matematika.

Fatkhiyah, Lutfiana. (2010). Bilangan Clique dan Faktorisasi pada Perkalian Graf Komplit. Hlm. 10. ETHESES UIN Malang.

Hasmawati, Prof. M.Si. (2015). Bahan Ajar Teori Graf. Hlm. 13-17. Universitas Hasanuddin.

Lipschutz, S. Dan Lipson, M.L. (2002). Matematika Diskrit 2. Terj. Tim Editor Penerbit Salemba Teknika. Jakarta: Salemba Teknika.

Mandailina, Vera. (2009). Faktorisasi pada Graf Komplit. Hlm. 18. ETHESES UIN Malang.

Mursyidah, H. dan Rahmawati, S. (2017). Dominating Number Dari Graf Hasil Operasi Korona Graf Lintasan Dengan Graf Sikel $P_{n} \odot C_{m}$ dan Sebaliknya $C_{m} \odot P_{n}$. HIm. 1. ITS.

Rahmawati, Nur. (2014). Dekomposisi Graf Sikel, Graf Roda, Graf Gir dan Graf Persahabatan. Jurnal UNESA. 3(3), 64-71.

Suryanto. (1986). Materi Pokok Pengantar Teori Graph. Jakarta: Karunika Universitas Terbuka. 